\title{
1 Arbuscular mycorrhizal fungal composition across US citrus orchards, management \\ 2 strategies, and disease severity spectrum
}

4 MengYuan $\mathrm{Xi}^{1}$, Elizabeth Deyett ${ }^{1}$, Nichole Ginnan ${ }^{2}$, Vanessa E.T.M. Ashworth ${ }^{1}$, Tyler Dang ${ }^{2}$,

5 Sohrab Bodaghi ${ }^{2}$, Georgios Vidalakis ${ }^{2}$, M. Caroline Roper ${ }^{2}$, Sydney I. Glassman ${ }^{2}$ and Philippe E.

6 Rolshausen ${ }^{1}$.

8 Corresponding authors:

9 Philippe E. Rolshausen

10 Tel: +19518276988

11 Email: philrols@ucr.edu

13 Sydney Glassman

$14 \quad$ Tel: +19518276727

15 Email: sydney.glassman@ucr.edu

\section{Summary}

18 Arbuscular mycorrhizal fungi (AMF) remain understudied in perennial cropping systems. Citrus

19 is a globally grown fruit tree and under threat by the pandemic Huanglongbing (HLB) disease.

20 Here, we assessed in what capacity geographical location, management strategies and disease

21 affect AMF citrus root communities. Root samples were collected from 88 trees in ten orchards

22 located in the two major citrus producing states in the US. Orchards were selected based on

23 conventional or organic practices in California and based on HLB symptom severity in Florida.

24 We used AMF-specific amplicon sequencing primers to capture community composition and

25 diversity. Taxa names were assigned based on a phylogenetic analysis that comprised a backbone

26 of AMF references sequences from Mycobank and virtual taxa from the MaarjAM database.

27 AMF were detected in $78 \%$ of citrus root samples with taxa belonging to six known (Dominikia,

28 Funneliformis, Glomus, Rhizophagus, Sclerocystis, Septoglomus) and unknown Glomeraceae

29 genera. Geographical location affected AMF community composition but not richness, whereas

30 management practice and disease influenced both richness and composition. Our approach 
31 indicated that perennial agroecosystems share a set of AMF generalist and specialist taxa. Some taxa could improve environmental fitness and be exploited for agricultural purposes.

\section{Introduction}

35 Arbuscular mycorrhizal fungi (AMF) are biotrophic organisms forming symbiotic associations with more than $70 \%$ of the land plants across a broad range of terrestrial ecosystems $(1,2)$. The nature of the mutualistic symbiosis resides in a trade-off between a more efficient root acquisition of water and nutrients (especially phosphorus) via the mycorrhizal hyphal network, in exchange for photo-assimilated carbon. The outcome of this interaction often results in improved plant environmental fitness with increased tolerance to biotic and abiotic stresses $(3,4)$. In addition, AMF improve soil structure by forming stable soil aggregates thereby limiting erosion and leaching of nutrients $(4,5)$.

Plant parts above and below ground are intricately connected and the health status of the root system often determines plant growth and productivity. The rhizosphere microbial diversity is a biomarker of soil fertility and plays a central role in sustainable agricultural systems $(6,7)$. Low input agriculture systems (organic and biodynamic farming) have adopted cultural practices to rely on soil biological metabolism and function to support soil fertility and plant root health. In contrast, intensive farming practices characterized by monoculture, input of synthetic agrochemicals, and/or soil disturbance caused by mechanical stress generally leads to degradation of soil ecosystem biodiversity. Mycorrhizal fungi are major participants of the rhizosphere microbiome and are under the constraints of farming practices, with research

52 indicating that mycorrhizal fungi are more diverse under organic agroecosystems $(8,9)$.

53 Understanding the factors that shape AMF communities could improve management tools and 54 recommendations for implementing more sustainable agricultural practices.

Citrus is a high-value crop and one of the most popular and widely grown fruit trees

56 globally. It is praised for its nutritional values and benefits to human health as a source of

57 vitamins, fibers, and minerals. Citrus accounts for $16 \%$ of the total value of U.S. fruit production

58 (10) with California and Florida leading the nation's fresh fruit and juice markets, respectively.

59 Symbiotic associations with AMF have been reported in all citriculture production areas and

60 AMF communities are shaped by edaphic characteristics, orchard management practices, and

61 host variety and age (11-14). Adopting low input farming practices for citrus at a large 
62 geographic scale has been challenging because of Huanglongbing (HLB), a disease associated

63 with an invasive phloem-limited bacteria in the Candidatus Liberibacter genus (i.e., C. L.

64 asiaticus, americanus, and africanus) (15). In the U.S., C. L. asiaticus is the primary threat to

65 citrus. The Florida citrus industry suffered a 74\% decline in production with losses amounting to

66 over $\$ 1$ billion annually because of $\operatorname{HLB}(10,16)$. The pathogen is vectored by an invasive insect

67 (Diaphorina citri; the Asian citrus psyllid) and disease management has been mostly achieved

68 by intensive regimens of synthetic insecticide applications to control insect populations (17). In

69 heavily affected orchards, trees are also treated with antibiotics (oxytetracycline and

70 streptomycin) to reduce levels of pathogen inoculum reservoirs (18). Those practices have raised

71 environmental concerns due to the risk of unintended consequences for biodiversity and selection

72 for resistance in bacterial and insect populations $(19,20)$.

73 In HLB-impacted orchards, the tree rhizosphere suffers from microbial dysbiosis and root

74 collapse, thereby weakening the host and its defense response against attack from other

75 pathogens $(21,22)$. Specifically, a study from Florida found that high relative abundance of

76 Glomeromycota correlated with healthier trees (22), although the ITS2 amplicon used in the

77 study limited the resolution of AMF taxonomy and may have omitted key taxa (23). AMF have

78 been established to provide protection against citrus root diseases $(24,25)$, and developing

79 practices that support their biodiversity can offer new ground for management strategies.

80 Previous studies have found at least seven genera of AMF associated with citrus roots

81 (Acaulospora, Entrophospora, Gigaspora, Glomus, Pacispora, Sclerocystis, and Scutellospora),

82 yet little is known about how these communities vary across geographies or management

83 practices. Moreover, many of these studies are morphological-based and may have

84 underrepresented AMF diversity that can be captured with sequencing approaches (26).

85 Citrus is an emblematic specialty crop to US agriculture. In the wake of the economic and

86 environmental challenges posed by HLB, alternative strategies to farming citrus should be

87 considered. This study aimed to profile AMF community composition and structure in citrus

88 agroecosystems from two distinct climatic zones within the continental US. We captured citrus

89 root-associated AMF diversity by employing AMF-specific amplicon sequencing primers (27,

90 28) to better identify taxa and capture the biodiversity associated with citrus roots. Orchards in

91 California were selected according to the farming practices (organic vs. conventional) and in

92 Florida according to severity of HLB disease symptoms expression (mild, moderate, severe) 
93 because HLB positive trees have not been detected in commercial groves in California. We

94 hypothesize that AMF community composition will overall differ between California and Florida

95 because temperature and $\mathrm{pH}$ are known to be major drivers of AMF composition globally and

96 these regions have inherently different climatic conditions and edaphic factors (29). We also

97 anticipate some level of overlap in AMF taxonomic distribution between these two citriculture

98 areas because of the similarity of the host. In addition, within each citrus area, we speculate that

99 organic farming will have higher AMF diversity than conventional farming and that HLB

100 affected trees will display fewer AMF symbionts because of the lower photoassimilated carbon

101 transfer to the host root system. This study provides insightful information about AMF dynamics

102 within a major perennial agroecosystem and identifies putative generalist and specialist taxa that

103 could be exploited for agricultural purposes.

104

105 Materials and Methods

106 Root sample collection: Root samples were collected from 88 trees in ten citrus orchards located

107 in Florida (ten trees per orchard) and California (eight trees per orchard) following published

108 protocols (22). In Florida, 40 samples were collected in March 2017 from four conventional

109 orchards (Table 1). All trees were rated for HLB symptoms using a disease rating scale ranging

110 from mildly, to moderately and severely symptomatic. In California, 48 samples were collected

111 in October 2017 from four conventional and two organic orchards (Table 1). For the California

112 sampling, feeder roots were sampled from two sides of the tree approximately $0.5 \mathrm{~m}$ away from

113 the base of the trunk and sealed in a plastic bag. Gloves were changed and clippers and shovels

114 were sterilized with $30 \%$ household bleach between each sampled tree. All samples were

115 immediately placed on ice in a cooler for transit to the laboratory and were frozen for shipment

116 to the University of California, Riverside (UCR). Root samples were rinsed with autoclaved

117 purified water (Barnstead Mega-Pure System MP-6a, Thermo Fisher Scientific, Waltham, MA,

$118 \mathrm{USA}$ ) and approximately $5 \mathrm{~g}$ of rinsed root tissue was placed into $50 \mathrm{ml}$ conical tubes, stored at -

$11980^{\circ} \mathrm{C}$, and then lyophilized (Labconco FreeZone 4.5L, Kansas City, MO) for 16 to 20 hours.

120 Samples were collected similarly in Florida and lyophilized prior to shipment to UCR under

121 USDA permit \#P526P-16-00352 on dry ice. 
DNA extraction, library construction and sequencing: DNA was extracted from roots according

124 to published protocols (22). Frozen and freeze-dried roots were crushed into small pieces $(<0.5$

$125 \mathrm{~cm})$ with sterile stainless-steel spatulas on dry-ice, and $100 \mathrm{mg}$ of freeze-dried tissue was

126 transferred to 2-ml microcentrifuge tubes (Eppendorf Safe-Lock tubes; Eppendorf, Hamburg,

127 Germany) containing a single 4-mm stainless-steel grinding ball (SPEX SamplePrep, Metuchen,

128 NJ, U.S.A.). Samples were chilled at $-80^{\circ} \mathrm{C}$ for $15 \mathrm{~min}$, then pulverized to a powder using a

$1292010 \mathrm{Geno} /$ Grinder (SPEX SamplePrep) at 1,680 rpm for 20 to 30 seconds, twice. Then, $1 \mathrm{ml}$ of

1304 M guanidine thiocyanate buffer was added to the pulverized root samples. Samples were

131 incubated at $4^{\circ} \mathrm{C}$ for $15 \mathrm{~min}$ and subsequently centrifuged for $1 \mathrm{~h}$ at 17,500 $\times \mathrm{g}$. DNA was

132 isolated using the MagMAX-96 DNA Multi-Sample Kit (Thermo Fisher Scientific) with the

133 protocol “4413021ForPlants” on a MagMAX Express-96 Deep Well Magnetic Particle

134 Processor. The final DNA was eluted in $100 \mathrm{ml}$ of DNA elution buffer and stored at $-20^{\circ} \mathrm{C}$ prior 135 to Illumina library construction.

136 DNA was PCR-amplified as described in Phillips et al. (30) targeting the 18S region

137 using the Glomeromycotina-specific AML2 and the universal eukaryote WANDA primer sets

138 (27, 28). Library construction was conducted in a two-step procedure (31) in which first-round

139 amplifications were carried out with primers possessing universal tails synthesized $5^{\prime}$ to the

140 locus-specific sequences (32) and second round-amplifications ligated Illumina MiSeq flowcell

141 adapters and barcodes (30). Recipe for PCR1 included $1 \mu 1$ of template DNA, $12.5 \mu 1$ AccuStart

142 II PCR ToughMix (2X) (Quantabio, Beverly, MA), $0.5 \mu$ l of each primer $(10 \mu \mathrm{M})$, and $10.5 \mu \mathrm{l}$

143 nuclease-free water, resulting in a $25 \mu \mathrm{l}$ reaction. Thermocycler conditions for PCR1 were as

144 follows: $2 \mathrm{~min}$ at $94^{\circ} \mathrm{C} ; 29$ cycles of $30 \mathrm{~s}$ at $94^{\circ} \mathrm{C}, 30 \mathrm{~s}$ at $60^{\circ} \mathrm{C}, 45 \mathrm{~s}$ at $68^{\circ} \mathrm{C}$. Reaction products

145 were verified on a 1\% agarose gel and purified using the AMPure XP magnetic Bead protocol

146 (Beckman Coulter Inc., Brea, CA, USA). PCR2 was performed in a $25 \mu$ reaction, with $1 \mu$ of

147 the undiluted purified PCR1 product, $6.5 \mu$ AccuStart II PCR ToughMix (2X) (Quantabio,

148 Beverly, MA), $2.5 \mu$ of each barcode primer $(1 \mu \mathrm{M})$, and $12.5 \mu 1$ nuclease-free water.

149 Thermocycler conditions for PCR 2 were as follows: 2 min at $94^{\circ} \mathrm{C} ; 9$ cycles of $30 \mathrm{~s}$ at $94^{\circ} \mathrm{C}, 30$

$150 \mathrm{~s}$ at $60^{\circ} \mathrm{C}, 1 \mathrm{~min}$ at $72^{\circ} \mathrm{C}$. We checked indexed PCR products on an agarose gel and pooled the

151 products by band strength as in Glassman et al. (33) with $1 \mu 1$ for strong bands, $2 \mu 1$ for medium

152 bands, and $3 \mu \mathrm{l}$ for weak bands prior to AMPure bead purification. The purified library was

153 quantified with a Qubit 4 Fluorometer (Thermo Fisher Scientific, Waltham, MA) and quality 
154 checked with an Agilent BioAnalyzer 2100 for size and concentration and sequenced with

155 Illumina MiSeq nano run ( 2 x $250 \mathrm{bp})$ at the UC Riverside Institute for Integrative Genome

156 Biology. Sequences were submitted to the National Center for Biotechnology Information

157 Sequence Read Archive under accession number SRPXXX.

Bioinformatics and taxonomy assignment: Initial quality filtering of sequences was done using

160 Trimmomatic (34) truncating reads once the average quality of 5 consecutive base pairs dropped

161 below a quality score of 20. Using DADA2 (v 1.14.1), reads were processed further to remove

162 reads with more than one $\mathrm{N}$ calls, ambiguous calls, reads identified as PhiX, reads that were too

163 short, and reads with more than 2 expected errors per DADA2's algorithm. DADA2 was also

164 used to dereplicate, learn error rates, and create an amplicon single variant (ASV) sequence table

165 (35). Samples with less than 1,000 reads were removed, as were taxa not identified as fungi via

166 the NCBI database. Rare taxa, defined as taxa which were prevalent in less than $2 \%$ of samples

167 were also removed. This additional filtering step resulted in 131 total ASVs and 1,085,960 reads.

168 Taxonomy was assigned using BLASTN and the MaarjAM database (36)(downloaded on April

169 1, 2020) using a cut-off e-value of 1e-50 and assigning virtual taxa (VT) based on lowest e-value

170 and best-annotated sample. MaarjAM is an AMF curated database that is standardized, and

171 comparable across research projects, and preserved in time (23). MaarjAM clustered the 131

172 ASVs into 32 unique VT, and with 1 sequence left unidentified by the MaarjAM database using

173 the parameters mentioned above. Genus names were assigned through the curation of a

174 maximum likelihood bootstrap tree using the Krüger et al. sequences (37). The 33 representative

175 sequences were $220 \mathrm{bp}$ in length and were aligned in Muscle v.3.7 (38) using default parameters

176 to the 58 consensus sequences from Krüger et al. (37) and updated by Stefani et al. (26). Twelve

177 sequences from GenBank were added, resulting in a total of 103 sequences and an alignment

178 length of 756 nucleotides, consisting of 508 conserved, 235 variable, 176 parsimony-

179 informative, and 57 singleton sites. A maximum likelihood tree was constructed in RAxML

180 v8.2.12 (39) implemented on the CIPRES Gateway (40) using a GTRGAMMA evolutionary

181 model of nucleotide substitution and with branch support inferred using 1000 bootstraps. The

182 tree was rooted using Paraglomus occultum as the outgroup as per Krüger et al. (37). The

183 consensus tree was visualized and annotated in iTOL (Interactive Tree of Life; (41)). 
Statistical analyses and data visualization: The R v4.1.1 (R Core Team, 2021) was used to perform statistical analysis and data visualization with the aid of the phyloseq v1.36.0 (42) and ggplot2 v3.3.5 packages (43). Data was transformed using the variance stabilization method in the DESeq package v1.32.0 (44). Alpha diversity was estimated as the number of observed taxa of each sample. Statistical significance was calculated by a generalized linear model using Poisson regression and statistical significance on pairwise comparison was performed through Tukey's test using the multcomp packages v1.4.17 (45). Beta-diversity plots were created using the Bray-Curtis dissimilarity matrix and NMDS ordination matrix using the Vegan package v2.5.7 (46). Adonis tests with 999 permutations were run to determine statistical differences between categorical variables. For heatmaps, created using ComplexHeatmap v2.9.4 (47), the normalized data were aggregated to the VT level and dataset split based on category. VT occurring in fewer than 3 samples of the dataset were removed for ease of visualization. This resulted in 27 taxa in the heatmap comparing California and Florida samples, 15 taxa in the heatmap comparing management strategy and 17 taxa in the heatmap comparing disease rating. For the Venn diagram, a 10\% prevalence filtering was applied to find unique and shared taxa amongst categories. Prevalence was defined as occurring at least 1 time in $10 \%$ of the samples within a category. Finally, DESeq2 (V1.32.0; (44)) using the default Wald test and local fit, was used to identify taxa with differential abundance analysis among variables of interest. For this analysis, taxa were aggregated to the VT level. Virtual taxa that had a p-value $<0.01$ are represented in the heat maps with a "*” symbol or by colored block.

\section{Results}

We detected AMF in 69 of the total 88 citrus root samples (78\%, Table 1) with a total of 131 ASVs and 33 virtual taxa. The maximum likelihood phylogenetic analysis that included several taxa from Krüger et al. (37) and the same outgroup (Paraglomus occultum), yielded a similar tree topology with strong bootstrap support at the Family level and indicated that all the VT belong to the Glomeraceae (Fig. 1). Taxonomic identification at the genus level was more challenging for some groups given the short nucleotide sequence length, but monophyletic clades with good bootstrap support were obtained for Sclerocystis, Glomus, and Septoglomus. The genus Rhizophagus clustered in a monophyletic clade, but with weak bootstrap support, and only formed a well-supported clade with Sclerocystis. Similarly, Funneliformis - though itself not a 
216 monophyletic group — formed a strongly supported clade with Septoglomus. Support for

217 Dominikia was low and good bootstrap support was obtained only for a subclade composed of

218 two VTs (VTX00222 and VTX00125) with Dominikia indica, and for a subclade composed of

219 D. iranica and VTX00155. Based on the tree phylogeny, we assigned twelve VTs (VTX00125, -

$220130,-132,-146,-155,-156,-159,-166,-175,-222,-304$ and 'Unknown') to Dominikia, ten VT

221 (VTX00080, -83, -92, -99, -100, -105, -113, -114, -115, -248) to Rhizophagus, four VT

222 (VTX00063, -64, -331, -409) to Septoglomus, one VT (VTX00197) to Glomus, and one VT

223 (VTX00067) to Funneliformis. Placement for five VTs (VTX00075, -214, -301, -323, -384)

224 remained uncertain as they did not cluster in any of those clades and were labeled as

225 Glomeraceae species.

226 Geographical location did not affect AMF richness in California and Florida citrus

227 orchards as indicated by similar alpha diversity indices (Fig.2A; $P>0.05$, Poisson generalized

228 linear model with a pairwise Tukey test), although AMF community composition was

229 significantly distinct between the two states (Fig. $3 \mathrm{~A}$; Adonis $\mathrm{R}^{2}=0.176, P<0.001$ ) with

230 specific taxa and differential abundance among taxa indicated in the heatmap (Fig. 4). Orchard

231 management strategy significantly affected alpha and beta diversity of AMF communities in

232 California, with lower taxa richness in conventional orchards (Fig. 2B; $P<0.0001$, Poisson

233 generalized linear model with a pairwise Tukey test) and higher compositional variability (i.e.,

234 dispersion) among conventional orchard than organically managed orchards (Fig. 3B; Adonis $\mathrm{R}^{2}$

$235=0.145, P<0.01$; betadisper $P<0.05)$. The differential abundance among taxa between organic

236 and conventional farming methods are indicated in the heatmap with compositionally less

237 diverse communities in the conventional orchards (Fig. 5). In Florida, HLB disease status

238 significantly impacted AMF community alpha diversity, with a decline in richness (Fig. 2C; $P<$

239 0.001, Poisson generalized linear model with a pairwise Tukey test) and shifts in community

240 composition as disease severity increased from mild to severe (Fig. 3C; $\mathrm{R}^{2}=0.167, P<0.05$;

241 Adonis). The differential abundance among taxa across the disease spectrum are indicated in the

242 heatmap with compositionally less diverse communities in severely HLB-symptomatic trees

243 (Fig. 6)

244 Our core taxa analysis identified nine generalist virtual taxa commonly associated with

245 citrus in both Florida and California orchards (Fig. 4) and included two Dominikia taxa

246 (VTX00156, -304), three Rhizophagus taxa (VTX00092, -100, -248), one Septoglomus taxon 
247 (VTX00063), and three unknown taxa within the Glomeraceae (VTX00214, -301, -323). The

248 remaining AMF taxa were associated with a single geographical location, and under specific

249 management practices or disease phenotype, which could imply specialized functions and/or

250 unique growth needs (Figs. 4-6). Therefore, we refer to these taxa as "specialist". Several taxa

251 from both the generalist and specialist groups were differentially abundant across geographical

252 location (Fig. 4; Wald's Test: $P<0.01$ ), including three generalist taxa (Rhizophagus

253 VTX00092, Septoglomus VTX00063, and unknown Glomeraceae VTX00214) and nine

254 specialist taxa, with five from Florida (Rhizophagus VTX00113 and -115; Dominikia VTX00222

255 and -125; unknown Glomeraceae VTX00384) and four from California (Dominikia VTX00155

256 and -130; Septoglomus VTX00409 and -64). Our data also indicated that organic and

257 conventional California orchards shared ten AMF taxa, including eight of the nine generalist

258 taxa. One generalist taxon (unknown Glomeraceae VTX00323) was only associated with

259 conventional orchards. In contrast, several AMF taxa were unique to organic orchards including

260 two Septoglomus (VTX00064, -331), one Rhizophagus (VTX00105), and three Dominikia

261 (VTX130, -175, and 'Unknown'), among which Dominikia VTX00130 and Septoglomus

262 VTX00064 were significantly enriched (Fig. 5: Wald's Test: $P<0.01$ ). In addition, AMF taxa

263 were clearly impacted by HLB as nine VT could not be detected in trees severely affected by

264 HLB (Fig. 6). Specifically, generalist unknown Glomeraceae VTX00323 and Dominikia

265 VTX00132 were significantly depleted as HLB symptoms became more severe and could

266 potentially serve as biological markers of tree health or HLB (Fig. 6: Wald's Test: $P<0.01$ ).

268 Discussion

269 Here, we report the first comprehensive study of AMF diversity among US citrus orchards in

270 different growing regions, under different management strategies, and under different levels of

271 disease severity using modern sequencing methods and computational analysis. We found that

272 AMF richness was similar between Florida and California and both citriculture regions shared a

273 set of generalist taxa. However, AMF community composition varied significantly among these

274 two distinct climatic zones with some specialist taxa being unique to a specific region. Our

275 results indicated that organic practices supported AMF diversity with a unique set of specialist

276 taxa not detected in conventionally farmed orchards. In addition, the worsening of disease 
symptoms severity in HLB impacted orchards induced a significant decrease in AMF richness accompanied with a drastic shift in community composition.

Our results indicate that citrus trees were commonly found (78\%) in association with AMF as reported in other systems $(1,2)$ and that AMF community composition in US orchards was more diverse than initially reported. The last comprehensive AMF study in California and Florida orchards was based on spore morphology and identified the cosmopolitan genus Glomus, as well as the two genera Gigaspora and Sclerocystis (11). Previous studies on citrus that have used morphology and DNA sequencing-based approaches also reported that Glomus species were dominant AMF taxa in orchards worldwide including Brazil (12), China $(13,48)$ and Spain (49). In contrast, we found a broader number of AMF genera including Dominikia,

Funneliformis, Glomus, Rhizophagus, Septoglomus, and likely additional undescribed genera within the Glomeraceae. Our results also indicated that Dominika and Rhizophagus were the most abundant genera associated with citrus roots, although the Dominikia group was not well supported. We achieved this fine-scale resolution of citrus-associated AMF clades by adopting a novel taxonomy assignment approach based on AMF-specific amplicons and developed by

292 Stefani et al. (26). This disparity between our results and previous reports can be explained by 293 the recent taxonomic revision of the Glomeromycota phylum in which the family Glomeraceae 294 was split into several families (http://www.amf-phylogeny.com/; (37)) and many Glomus species 295 were moved to different genera. Based on this fact, our results partially corroborate previous 296 findings. Hence, the Glomus virtual taxa associated with citrus in China identified by Song et al.

297 (48) based on the MaarjAM database, clustered in our analysis with Rhizophagus, Glomus,

298 Septoglomus and Dominikia. Furthermore, Glomus fasciculatus and G. constrictus, identified by

299 Nemec et al. (11) using spore morphology have now been renamed Rhizophagus fasciculatus and

300 Septoglomus constrictum, respectively, both of which were clearly identified in our study.

301 However, we did not identify taxa outside of the Glomeraceae, whereas Gigaspora spp.

302 (Gigasporaceae) and Glomus etunicatus (now named Claroideoglomus etunicatum,

303 Claroideoglomeraceae) were previously described by Nemec et al. (11). This difference may be 304 due to our sampling size, seasonal variation (50), temporal variation (nearly 40 years between 305 sampling events), location and edaphic properties of orchards sampled (29), and variety of citrus 306 sampled (14), which can all affect AMF composition. Together these results suggest that the 
AMF communities associated with trees in citriculture across the globe are composed of a diverse set of taxa.

The AMF community in Florida and California was composed of virtual taxa that were shared in both states while others were specific to each state. The most abundant and common virtual taxa within the genera Dominikia (VTX00156, VTX304), Rhizophagus (VTX00092 and

312 VTX00248), Septoglomus (VTX00063) and unidentified Glomeraceae species (VTX00214 and

313 VTX00301), were also associated with citrus in China (48), apple in Italy (51), and barrel medic

314 (Medicago truncatula) in Tunisia (52) suggesting that they are not specific to citrus or the US.

315 Rhizophagus fasciculatus and Septoglomus constrictum have been classified as generalist AM

316 fungi capable of colonizing a broad range of soils (8), and our data corroborate these findings. In

317 fact, Rhizophagus species have been used broadly in agriculture to improve soil, promote host

318 plant growth, and cope with diseases $(53,54)$. However, the nature of the interaction between

319 AMF and its host are context dependent and may not always result in beneficial mutualistic

320 outcomes $(55,56)$. Moreover, the specialist Rhizophagus taxa identified in Florida (VTX00113

321 and -115), were previously found in Tunisia (52) perhaps indicating that some environmental

322 conditions in those geographic areas were not present in California. Additional sampling will

323 need to be performed from citrus-producing areas to classify specialist from generalist taxa and

324 identify those that confer beneficial functions on citrus with potential to be deployed as

325 probiotics commercially. Overall, these data support the global distribution of ubiquitous taxa

$326(36,57)$. The community segregation in the two distinct citrus climatic zones within the

327 continental US indicates that community composition is driven by environmental conditions and 328 ecological requirements of $\operatorname{AMF}(58)$.

329 Our study also took advantage of modern sequencing methods to evaluate the impact of

330 farming practices on AMF community richness and composition. Farming practices and soil

331 characteristics have been recognized to affect soil microbial biodiversity and fertility $(6,7)$.

332 AMF are major components of soil agroecosystem structure, functionality, and productivity, and

333 low input agricultural practices (e.g., organic farming) have been shown to be conducive to AMF

334 biodiversity, activity, and root colonization in both annual $(9,59)$ and perennial cropping

335 systems $(12,51)$. Our results support those findings as we measured distinct AMF community

336 profiles in organic orchards in comparison to nearby conventional orchards. In addition, several

337 virtual taxa, including Rhizophagus (VTX00105) and Septoglomus (VTX00064), were 
specifically enriched in organic orchards. Exogenous application of $S$. constrictum and $R$.

intraradices stimulated plant growth or productivity in several cropping systems and increased tolerance to heat and drought stress $(60,61)$. Soil organic matter content, $\mathrm{pH}$ and phosphorus availability are major factors that shape AMF community composition and assemblage $(8,29)$, and one can speculate that edaphic factors were affected under organic farming practices and in turn influenced the symbiotic relationship between AMF and citrus roots. Additional research will need to evaluate if $S$. constrictum and $R$. intraradices provide some fitness advantage for citrus trees under the semi-arid conditions of California's primary citrus growing areas.

We found conclusive evidence that increased severity of HLB disease negatively impacts AMF richness, which corroborates previous findings using ITS2 amplicons (22). We used the same citrus root samples from Florida collected by Ginnan et al. (22) but sequenced the 18S rDNA in place of the ITS region, which is a more robust approach to quantify and profile the Glomeromycota $(27,28,62)$. Our data confirmed a depletion of AMF richness and shifts in community composition as HLB severity worsened. AMF are obligate plant root symbionts and as such are greatly dependent on the host root carbon resources for metabolic processes. Trees expressing severe HLB symptoms, with thin canopy, small leaves, and branch dieback also show significant root collapse. These symptoms are caused by carbon sequestration in the aboveground tissues and poor belowground translocation of photoassimilates leading to root carbohydrate starvation (63) and likely results in a disturbance of the symbiosis with AMF. In

357 parallel, the mycorrhizal decline was also coupled with a significant increase in parasitic fungi and oomycetes (i.e., Fusarium and Phytophthora) of the host rhizosphere and this enrichment of root-associated parasites was proposed to contribute to the root decline and hasten the decline of trees impacted with HLB (22). Several studies have highlighted the instrumental role of AMF in delaying disease onset or reducing symptoms against the soilborne pathogens Fusarium and Phytophthora in several pathosystems $(64,65)$ including citrus $(24,25)$. An AMF-induced

363 disease resistance mechanism has been described as an integrated part of the symbiosis between

364 the host and its AMF-associated root community. Hence, the host defense response can be either 365 localized in the roots or systemic throughout the plant and can be activated either constitutively 366 or primed upon pathogen attack (3). We propose that citriculture practices that foster AMF-citrus 367 root symbioses may be able to sustain tree health under disease pressure and especially expand 368 tree longevity and productivity in the context of HLB. 
In conclusion, our unique and innovative approach to study rhizosphere mycobiome has greatly increased our understanding of AMF communities in citrus and perennial agroecosystems at large. A comprehensive and robust taxonomic assignment will benefit future AMF-root host

372 interaction inquiries with major implications for improving citrus protection and yield.

\section{Acknowledgements}

375 We acknowledge James Randolph's contribution for training MengYuan Xi in molecular

376 methods. We thank the California Citrus Research Board (Grant Numbers 5300-164 and 6100),

377 the California Department of Food and Agriculture (Grant Number SCB16056) and National

378 Institute of Food and Agriculture (Grant Number 2017-70016-26053) for funding support. We

379 also acknowledge the National Science Foundation Graduate Research Fellowship Program

380 Directorate for Biological Sciences (Grant Number NSF DGE-1326120). Any opinions, findings,

381 and conclusions or recommendations expressed in this material are those of the author(s) and do

382 not necessarily reflect the views of the National Science Foundation.

\section{Author contributions}

385 PER, SIG, MCR, and GV designed the project. PER, NG, TD, SB collected root samples. NG,

386 TD and SB extracted DNA from samples. MYX prepared DNA libraries. MYX, ED and

387 VETMA performed computational and/or phylogenetic and created the figures. PER, SIG, MYX

388 and ED wrote the manuscript. Everyone contributed significantly to the manuscript and gave

389 final approval for publication.

\section{References}

392 1. Smith SE, Read DJ. 2008. Mycorrhizal symbiosis. Academic Press, New York, NY.

393 2. Brundrett MC, Tedersoo L. 2018. Evolutionary history of mycorrhizal symbioses and 394 global host plant diversity. New Phytol 220:1108-1115.

395 3. Hohmann P, Messmer MM. 2017. Breeding for mycorrhizal symbiosis: focus on disease 396 resistance. Euphytica 213:113.

397 4. Chen M, Arato M, Borghi L, Nouri E, Reinhardt D. 2018. Beneficial services of arbuscular mycorrhizal fungi-from ecology to application. Front Plant Sci 9:1270. 
5. Wilson GWT, Rice CW, Rillig MC, Springer A, Hartnett DC. 2009. Soil aggregation and carbon sequestration are tightly correlated with the abundance of arbuscular mycorrhizal

6. Mäder P, Fließbach A, Dubois D, Gunst L, Fried P, Niggli U. 2002. Soil fertility and fungi: results from long-term field experiments. Ecol Lett 12:452-461.

7. Hartmann M, Frey B, Mayer J, Mäder P, Widmer F. 2015. Distinct soil microbial diversity under long-term organic and conventional farming. ISME J 9:1177-1194.

8. Oehl F, Laczko E, Bogenrieder A, Stahr K, Bösch R, van der Heijden M, Sieverding E. 2010. Soil type and land use intensity determine the composition of arbuscular

9. Verbruggen E, Röling WFM, Gamper HA, Kowalchuk GA, Verhoef HA, van der Heijden MGA. 2010. Positive effects of organic farming on below-ground mutualists: large-scale

10. Li S, Wu F, Duan Y, Singerman A, Guan Z. 2020. Citrus greening: Management strategies and their economic impact. HortScience 55:604-612.

415 11. Nemec S, Menge JA, Platt RG, Johnson EL V. 1981. Vesicular-arbuscular mycorrhizal fungi associated with citrus in Florida and California and notes on their distribution and

418 12. Franca SC, Gomes-da-Costa SM, Silveira APD. 2007. Microbial activity and arbuscular ecology. Mycologia 73:112-127. mycorrhizal fungal diversity in conventional and organic citrus orchards. Biol Agric

421 13. Wang P, Zhang JJ, Shu B, Xia RX. 2012. Arbuscular mycorrhizal fungi associated with citrus orchards under different types of soil management, southern China. Plant, Soil Environ 58:302-308. 
424 14. Song F, Pan Z, Bai F, An J, Liu J, Guo W, Bisseling T, Deng X, Xiao S. 2015. The scion/rootstock genotypes and habitats affect arbuscular mycorrhizal fungal community in

15. Bové JM. 2006. Huanglongbing: a destructive, newly-emerging, century-old disease of citrus. Front Microbiol 6:1372.

16. Court CD, Hodges AW, Rahmani M, Spreen T. 2018. Economic contributions of the Florida citrus industry in 2015-16: FE1021, 7/2017. EDIS 2018.

17. Boina DR, Bloomquist JR. 2015. Chemical control of the Asian citrus psyllid and of huanglongbing disease in citrus. Pest Manag Sci 71:808-823.

18. Hu J, Jiang J, Wang N. 2018. Control of citrus Huanglongbing via trunk injection of plant defense activators and antibiotics. Phytopathology 108:186-195.

19. Wood TJ, Goulson D. 2017. The environmental risks of neonicotinoid pesticides: a review of the evidence post 2013. Environ Sci Pollut Res 24:17285-17325.

20. McKenna M. 2019. Antibiotics set to flood Florida's troubled orange orchards. Nature $567: 302-304$.

21. Fan J, Chen C, Achor DS, Brlansky RH, Li Z-G, Gmitter Jr FG. 2013. Differential anatomical responses of tolerant and susceptible citrus species to the infection of

22. Ginnan NA, Dang T, Bodaghi S, Ruegger PM, McCollum G, England G, Vidalakis G, 'Candidatus Liberibacter asiaticus.' Physiol Mol Plant Pathol 83:69-74.

446 23. Lekberg Y, Vasar M, Bullington LS, Sepp S-K, Antunes PM, Bunn R, Larkin BG, Öpik 220:971-976. 
24. Watanarojanaporn N, Boonkerd N, Wongkaew S, Prommanop P, Teaumroong N. 2011. Selection of arbuscular mycorrhizal fungi for citrus growth promotion and Phytophthora suppression. Sci Hortic (Amsterdam) 128:423-433.

25. Tian L, Zou Y-N, Wu Q-S, Kuča K. 2021. Mycorrhiza-induced plant defence responses in trifoliate orange infected by Phytophthora parasitica. Acta Physiol Plant 43:1-8.

26. Stefani F, Bencherif K, Sabourin S, Hadj-Sahraoui AL, Banchini C, Séguin S, Dalpé Y. 2020. Taxonomic assignment of arbuscular mycorrhizal fungi in an 18S metagenomic

27. Lee J, Lee S, Young JPW. 2008. Improved PCR primers for the detection and identification of arbuscular mycorrhizal fungi. FEMS Microbiol Ecol 65:339-349.

28. Dumbrell AJ, Ashton PD, Aziz N, Feng G, Nelson M, Dytham C, Fitter AH, Helgason T. 2011. Distinct seasonal assemblages of arbuscular mycorrhizal fungi revealed by massively parallel pyrosequencing. New Phytol 190:794-804.

29. Davison J, Moora M, Semchenko M, Adenan SB, Ahmed T, Akhmetzhanova AA, Alatalo JM, Al-Quraishy S, Andriyanova E, Anslan S. 2021. Temperature and pH define the

30. Phillips ML, Weber SE, Andrews LV, Aronson EL, Allen MF, Allen EB. 2019. Fungal community assembly in soils and roots under plant invasion and nitrogen deposition. Fungal Ecol 40:107-117.

31. Berry D, Ben Mahfoudh K, Wagner M, Loy A. 2012. Barcoded primers used in multiplex

471 32. Alvarado P, Teixeira M de M, Andrews L, Fernandez A, Santander G, Doyle A, Perez M, Yegres F, Barker BM. 2018. Detection of Coccidioides posadasii from xerophytic environments in Venezuela reveals risk of naturally acquired coccidioidomycosis infections. Emerg Microbes Infect 7:1-13. 
33. Glassman SI, Weihe C, Li J, Albright MBN, Looby CI, Martiny AC, Treseder KK, Allison SD, Martiny JBH. 2018. Decomposition responses to climate depend on microbial community composition. Proc Natl Acad Sci 115:11994-11999.

34. Bolger AM, Lohse M, Usadel B. 2014. Trimmomatic: a flexible trimmer for Illumina sequence data. Bioinformatics 30:2114-2120.

35. Callahan BJ, McMurdie PJ, Rosen MJ, Han AW, Johnson AJA, Holmes SP. 2016. DADA2: high-resolution sample inference from Illumina amplicon data. Nat Methods

36. Öpik M, Vanatoa A, Vanatoa E, Moora M, Davison J, Kalwij JM, Reier Ü, Zobel M. 2010. The online database MaarjAM reveals global and ecosystemic distribution patterns in arbuscular mycorrhizal fungi (Glomeromycota). New Phytol 188:223-241.

37. Krüger M, Krüger C, Walker C, Stockinger H, Schüßler A. 2012. Phylogenetic reference data for systematics and phylotaxonomy of arbuscular mycorrhizal fungi from phylum to

38. Edgar RC. 2004. MUSCLE: multiple sequence alignment with high accuracy and high throughput. Nucleic Acids Res 32:1792-1797.

39. Stamatakis A. 2014. RAxML version 8: a tool for phylogenetic analysis and post-analysis of large phylogenies. Bioinformatics 30:1312-1313.

40. Miller MA, Pfeiffer W, Schwartz T. 2010. Creating the CIPRES Science Gateway for inference of large phylogenetic trees, p 1-8. In 2010 gateway computing environments workshop (GCE). Ieee.

496 41. Letunic I, Bork P. 2019. Interactive Tree Of Life (iTOL) v4: recent updates and new developments. Nucleic Acids Res 47:W256-W259. analysis and graphics of microbiome census data. PLoS One 8:e61217. 
43. Wickham H. 2016. ggplot2: elegant graphics for data analysis. Springer International Publishing, Cham, Switzerland.

44. Love MI, Huber W, Anders S. 2014. Moderated estimation of fold change and dispersion for RNA-seq data with DESeq2. Genome Biol 15:550.

45. Hothorn T, Bretz F, Westfall P. 2008. Simultaneous inference in general parametric models. Biometrical J J Math Methods Biosci 50:346-363.

46. Oksanen J, Blanchet FG, Friendly M, Kindt R, Legendre P, McGlinn D, Minchin PR, O’Hara RB, Simpson GL, Solymos P. 2020. vegan: community ecology package. R package version 2.5-6. 2019.

47. Gu Z, Eils R, Schlesner M. 2016. Complex heatmaps reveal patterns and correlations in multidimensional genomic data. Bioinformatics 32:2847-2849.

48. Song F, Bai F, Wang J, Wu L, Jiang Y, Pan Z. 2020. Influence of citrus scion/rootstock genotypes on arbuscular mycorrhizal community composition under controlled environment condition. Plants 9:1-16.

49. Camprubí A, Calvet C. 1996. Isolation and screening of mycorrhizal fungi from citrus nurseries and orchards and inoculation studies. HortScience 31:366-369.

50. Gao C, Montoya L, Xu L, Madera M, Hollingsworth J, Purdom E, Hutmacher RB, Dahlberg JA, Coleman-Derr D, Lemaux PG, Taylor JW. 2019. Strong succession in arbuscular mycorrhizal fungal communities. ISME J 13:214-226.

51. Turrini A, Agnolucci M, Palla M, Tomé E, Tagliavini M, Scandellari F, Giovannetti M. 2017. Species diversity and community composition of native arbuscular mycorrhizal fungi in apple roots are affected by site and orchard management. Appl Soil Ecol 116:4254.

52. Mahmoudi N, Cruz C, Mahdhi M, Mars M, Caeiro MF. 2019. Arbuscular mycorrhizal fungi in soil, roots and rhizosphere of Medicago truncatula: diversity and heterogeneity under semi-arid conditions. PeerJ 7:e6401. 
53. Ceballos I, Ruiz M, Fernández C, Peña R, Rodríguez A, Sanders IR. 2013. The in vitro mass-produced model mycorrhizal fungus, Rhizophagus irregularis, significantly increases yields of the globally important food security crop cassava. PLoS One 8:e70633.

54. Pawlowski ML, Hartman GL. 2020. Reduction of sudden death syndrome foliar symptoms and Fusarium virguliforme DNA in roots inoculated with Rhizophagus intraradices. Plant Dis 104:1415-1420.

55. Bever JD, Morton JB, Antonovics J, Schultz PA. 1996. Host-dependent sporulation and species diversity of arbuscular mycorrhizal fungi in a mown grassland. J Ecol 84:71-82.

56. Klironomos JN. 2003. Variation in plant response to native and exotic arbuscular mycorrhizal fungi. Ecology 84:2292-2301.

57. Öpik M, Metsis M, Daniell TJ, Zobel M, Moora M. 2009. Large-scale parallel 454 sequencing reveals host ecological group specificity of arbuscular mycorrhizal fungi in a boreonemoral forest. New Phytol 184:424-437.

58. Öpik M, Zobel M, Cantero JJ, Davison J, Facelli JM, Hiiesalu I, Jairus T, Kalwij JM, Koorem K, Leal ME, Liira J, Metsis M, Neshataeva V, Paal J, Phosri C, Põlme S, Reier Ü, Saks Ü, Schimann H, Thiéry O, Vasar M, Moora M. 2013. Global sampling of plant roots expands the described molecular diversity of arbuscular mycorrhizal fungi. Mycorrhiza 23:411-430.

59. Oehl F, Sieverding E, Ineichen K, Mäder P, Boller T, Wiemken A. 2003. Impact of land use intensity on the species diversity of arbuscular mycorrhizal fungi in agroecosystems of Central Europe. Appl Environ Microbiol 69:2816-2824.

60. Li T, Lin G, Zhang X, Chen Y, Zhang S, Chen B. 2014. Relative importance of an

550 61. Ziane H, Meddad-Hamza A, Beddiar A, Gianinazzi S. 2017. Effects of arbuscular arbuscular mycorrhizal fungus (Rhizophagus intraradices) and root hairs in plant drought tolerance. Mycorrhiza 24:595-602. mycorrhizal fungi and fertilization levels on industrial tomato growth and production. Int $\mathbf{J}$ Agric Biol 19:341-347. 
62. Lekberg Y, Arnillas CA, Borer ET, Bullington LS, Fierer N, Kennedy PG, Leff JW, Luis AD, Seabloom EW, Henning JA. 2021. Nitrogen and phosphorus fertilization consistently favor pathogenic over mutualistic fungi in grassland soils. Nat Commun 12:1-8.

63. Etxeberria E, Gonzalez P, Achor D, Albrigo G. 2009. Anatomical distribution of abnormally high levels of starch in HLB-affected Valencia orange trees. Physiol Mol Plant Pathol 74:76-83.

64. Alaux P-L, César V, Naveau F, Cranenbrouck S, Declerck S. 2018. Impact of Rhizophagus irregularis MUCL 41833 on disease symptoms caused by Phytophthora infestans in potato grown under field conditions. Crop Prot 107:26-33. sativa L.) with Funnelliformis mosseae and Sinorhizobium medicae can reduce Fusarium wilt. J Appl Microbiol 129:665-679. 
577 Table 1: Location and farming practices for the citrus orchards sampled in this study.

\begin{tabular}{|c|c|c|c|c|c|c|}
\hline $\begin{array}{c}\text { Orchard } \\
\#\end{array}$ & US State & $\begin{array}{c}\text { Number of } \\
\text { Root Samples } \\
\text { Collected }\end{array}$ & $\begin{array}{c}\text { Orchard } \\
\text { Type }\end{array}$ & Scion Variety & Rootstock & $\begin{array}{c}\text { Number of } \\
\text { Root samples } \\
\text { with AMF }\end{array}$ \\
\hline 1 & Florida & 10 & Conventional & Valencia & Swingle & 9 \\
\hline 2 & Florida & 10 & Conventional & Ruby Red & US897 & 9 \\
\hline 3 & Florida & 10 & Conventional & Parson Brown & Swingle & 9 \\
\hline 4 & Florida & 10 & Conventional & Hamlin & Sour Orange & 6 \\
\hline 5 & California & 8 & Conventional & Newhall x Satsuma & Carrizo & 7 \\
\hline 6 & California & 8 & Conventional & Late Navel Powell & Carrizo & 8 \\
\hline 7 & California & 8 & Conventional & Late Navel Powell & Carrizo & 2 \\
\hline 8 & California & 8 & Conventional & Late Navel Powell & Carrizo & 4 \\
\hline 9 & California & 8 & Organic & Newhall x Satsuma & Carrizo & 7 \\
\hline 10 & California & 8 & Organic & Late Navel Powell & Carrizo & 8 \\
\hline
\end{tabular}

579 Figure 1. RAxML phylogenetic tree reconstructed by maximum likelihood analysis showing the

580 genus taxonomy assignment of the 33 virtual taxa (in red). The tree represents 18 AMF genera

581 and VT clustered with 5 colored AMF clades. Bootstrap values greater than 70 are displayed on

582 the nodes.

584 Figure 2. Alpha diversity plots comparing AMF richness across sample types; geographical

585 location (A) shows no effect on richness, unlike management strategies (B) and HLB disease

586 (C). Statistical significance is indicated for $P<0.001(* * *)$ based on Poisson generalized linear 587 model with a pairwise Tukey test. 
Figure 3: NMDS plots indicating that AMF beta diversity is significantly affected across sample types based on; (A) geographic location (A); management strategies in California (B); and HLB disease in Florida (C). Each dot represents the AMF community composition of a single tree. Points are colored by each group $\mathrm{P}$-values and $\mathrm{R}^{2}$ values were measured by permutational multivariate analysis of variance (Adonis) with values shown on the graphs.

Figure 4: Heatmap of virtual taxa counts between geographical location following Deseq2 variance stabilization transformation. Each row represents a single root sample, and each column represents a unique virtual taxon. For clarity only virtual taxa that occurred in three or more samples are displayed. Top column annotation depicts the genus to which the virtual taxa clustered with based on Maximum likelihood tree in figure 1. Asterisk (*) depict virtual taxa differentially significantly abundant between geographical location per DESeq2 Wald's test.

601 Column annotation bar graph depicts the prevalence (number of unique samples) the virtual taxa

602 were found in. The "Association" column annotation is a colorimetric Venn diagram with a 10\% 603 prevalence cut-off where yellow squares represent taxa associated with California samples, blue 604 squares represent taxa associated with Florida samples and green squares represent taxa which 605 were associated with both Florida and California citrus roots. Gray boxes indicate taxa that did 606 not pass the $10 \%$ prevalent cut-off to be associated with either category. Row annotations show 607 which samples belong to each geographical location and bar graph shows the number of unique 608 ASVs associated with each sample. Dk: Dominikia; Fu: Funneliformis; Rz: Rhizophagus; Sg: 609 Septoglomus; Uk: Unknown.

611 Figure 5. Heatmap of virtual taxa counts between management strategy from California samples 612 following Deseq2 variance stabilization transformation. Each row represents a single root

613 sample, and each column represents a unique virtual taxon. For clarity only virtual taxa that

614 occurred in three or more samples are displayed. Top column annotation depicts the genus to

615 which the virtual taxa clustered with based on Maximum likelihood tree in figure 1. Asterisk (*)

616 depict virtual taxa differentially abundant between geographical location per DESeq2 Wald's

617 test. Column annotation bar graph depicts the prevalence (number of unique samples) the virtual 618 taxa were found in. The "Association" column annotation is a colorimetric Venn diagram with a 
$61910 \%$ prevalence cut-off where dark pink squares represent taxa associated with Conventional

620 samples, lavender squares represent taxa associated with Organic samples and medium pink

621 squares represent taxa which were associated with both Organic and Conventional citrus roots.

622 Row annotations show which samples belong to which management strategy and bar graph

623 shows the number of unique ASVs associated with each sample. Dk: Dominikia; Fu:

624 Funneliformis; Rz: Rhizophagus; Sg: Septoglomus; Uk: Unknown.

626 Figure 6. Heatmap of virtual taxa counts of HLB disease severity from Florida samples

627 following Deseq2 variance stabilization transformation. Each row represents a single root

628 sample, and each column represents a unique virtual taxon. For clarity only virtual taxa that

629 occurred in three or more samples are displayed. Top column annotation depicts the genus to

630 which the virtual taxa clustered with based on Maximum likelihood tree in figure 1. Asterisk (*)

631 depict virtual taxa differentially abundant between geographical location per DESeq2 Wald's

632 test. Column annotation bar graph depicts the prevalence (number of unique samples) the virtual

633 taxa were found in. Row annotations show which samples belong to each disease rating severity

634 and bar graph shows the number of unique ASVs associated with each sample. Venn diagram

635 heatmap with yellow rectangles show which taxa were found in at least $10 \%$ of sample from

636 each disease severity. Dk: Dominikia; Rz: Rhizophagus; Sg: Septoglomus; Uk: Unknown. 
bioRxiv preprint doi: https://doi. org/10.1101/2022 03.01.482593: this version posted March 2 2022. The copyright holder for this preprint (which was not certified by peer review) is the author/funder, who has granted bioRxiv a license to display the preprint in perpetuity. It is made available under aCC-BY-NC-ND 4.0 International license.

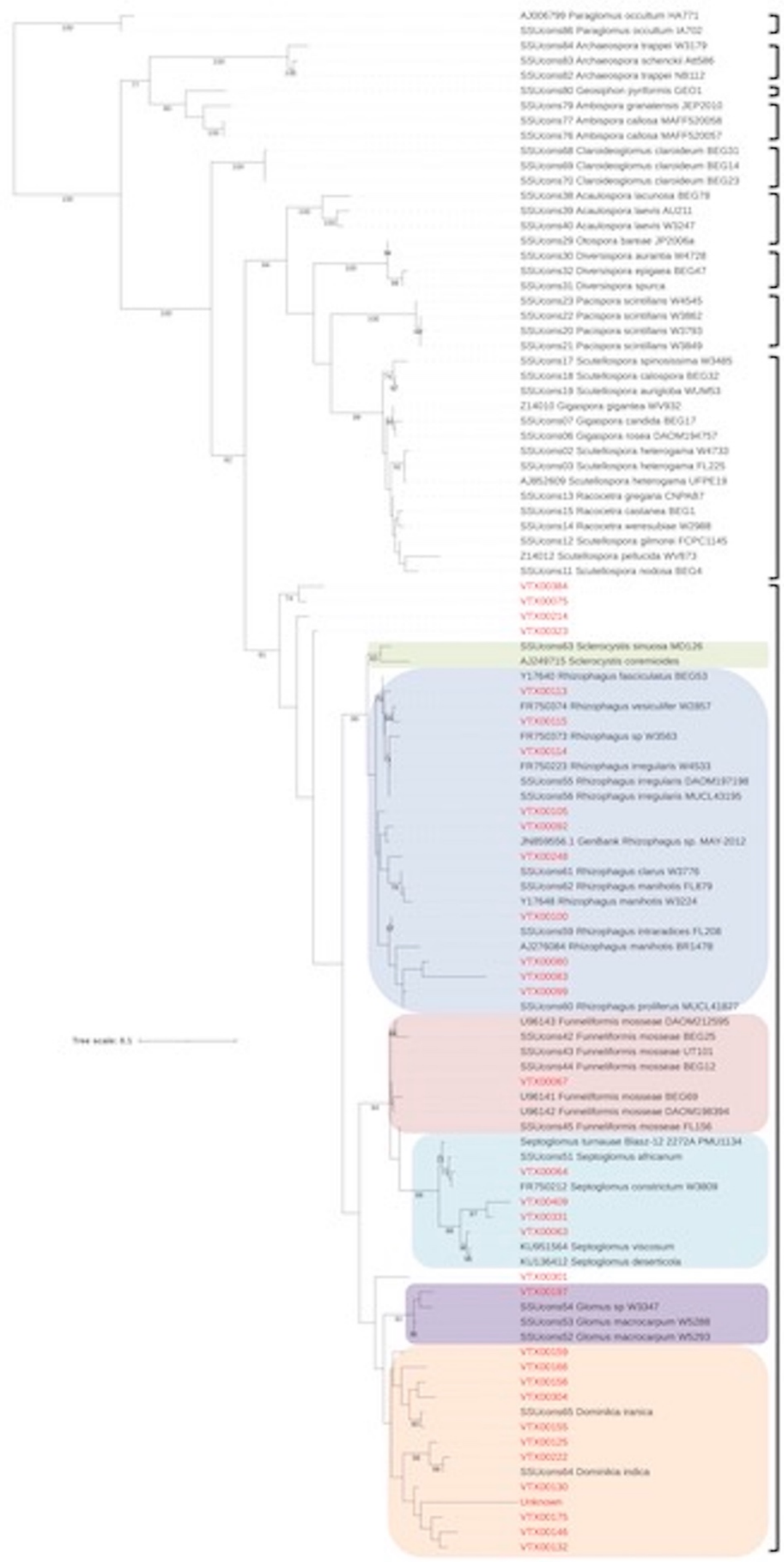

\author{
Paraglomeraceae \\ Archaeosporaceae \\ Geosiphonaceae \\ Ambisporaceae
}

Claroideoglomeraceae

Acaulosporaceae

Diversisporaceae

Pacisporaceae

Gigasporaceae

\section{Glomeraceae}


bioRxiv preprint doi: https://doi.org/10.1101/2022.03.01.482593; this version posted March 2, 2022. The copyright holder for this preprint (which was not certified by peer review) is the author/funder, who has granted bioRxiv a license to display the preprint in perpetuity. It is made available under aCC-BY-NC-ND 4.0 International license.

Figure 1. RAxML phylogenetic tree reconstructed by maximum likelihood analysis showing the genus taxonomy assignment of the 33 virtual taxa (in red). The tree represents 18 AMF genera and VT clustered with 5 colored AMF clades. Bootstrap values greater than 70 are displayed on the nodes. 


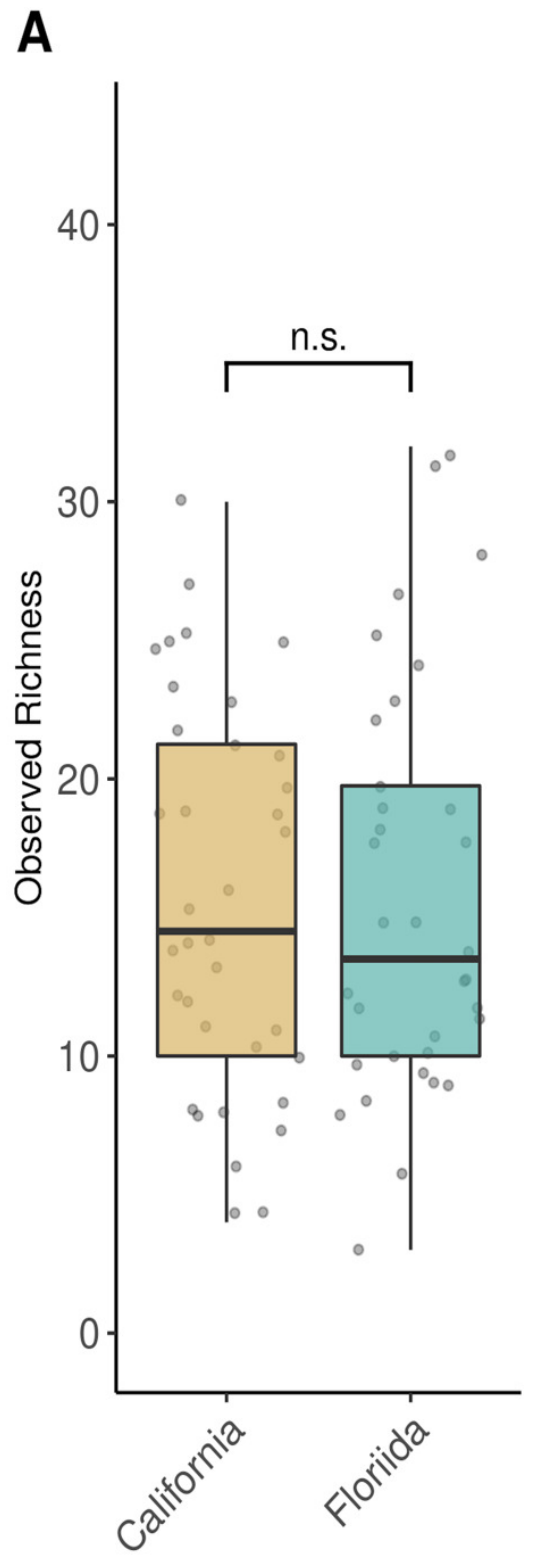

Geographical
B

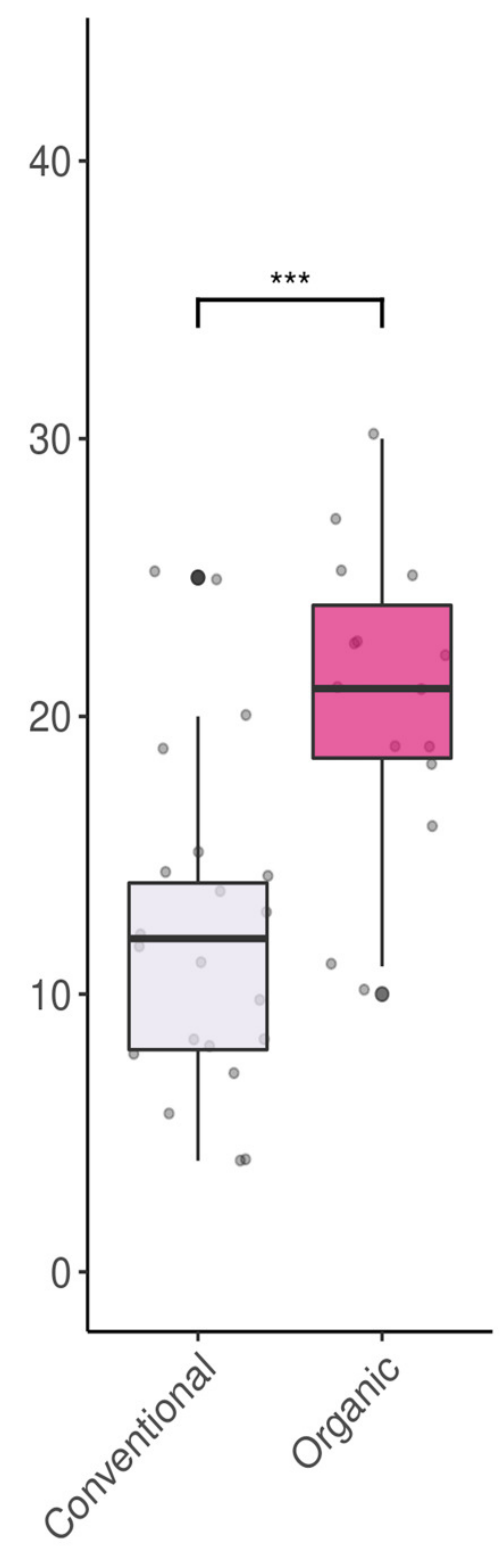

Management
C

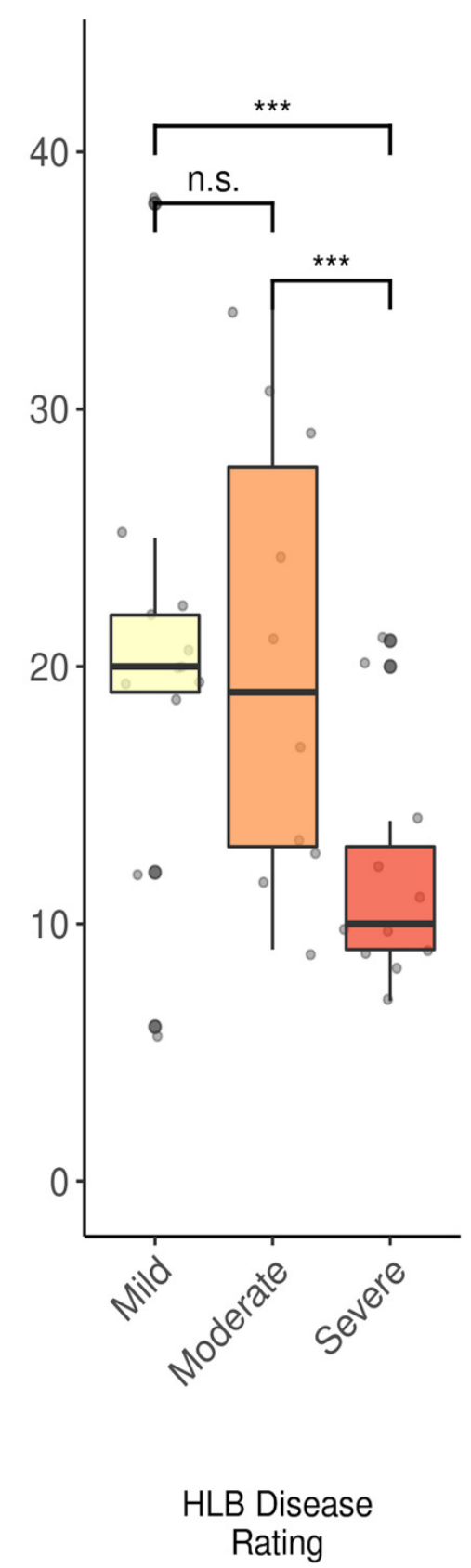

Figure 2. Alpha diversity plots comparing AMF richness across sample types; geographical location (A) shows no effect on richness, unlike management strategies (B) and HLB disease (C). Statistical significance is indicated for $P<0.001(* * *)$ based on Poisson generalized linear model with a pairwise Tukey test 

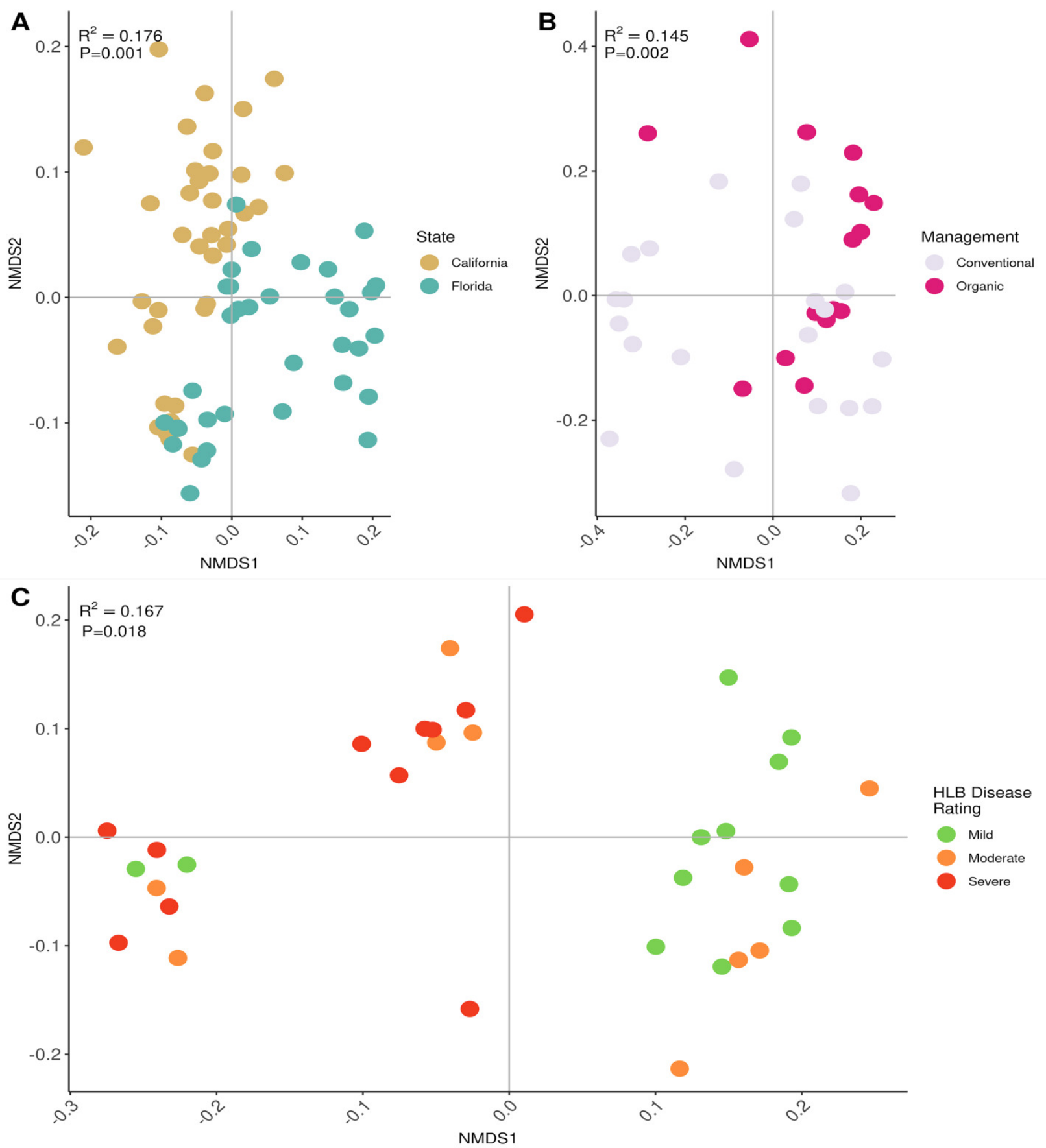

Figure 3: NMDS plots indicating that AMF beta diversity is significantly affected across sample types based on; (A) geographic location (A); management strategies in California (B); and HLB disease in Florida (C). Each dot represents the AMF community composition of a single tree. Points are colored by each group P-values and $R^{2}$ values were measured by permutational multivariate analysis of variance (Adonis) with values shown on the graphs. 
bioRxiv preprint doi: https://doi.org/10.1101/2022 03.01.482593. this version posted March 22022 The copyright holder for this preprin (which was not certified by peer review) is the author/funder, who has granted bioRxiv a license to display the preprint in perpetuity. It is made available under aCC-BY-NC-ND 4.0 International license.

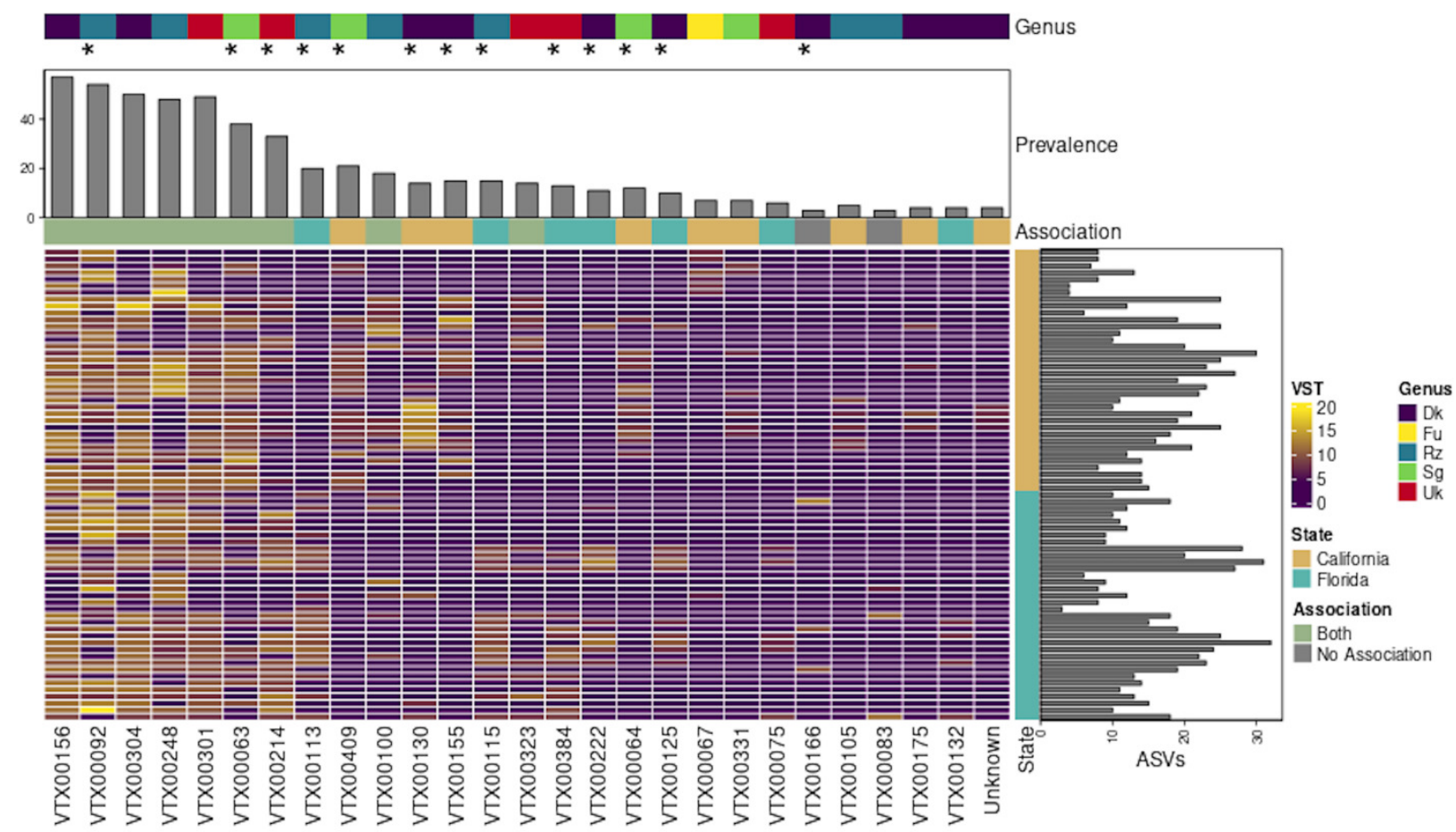

Figure 4: Heatmap of virtual taxa counts between geographical location following Deseq2 variance stabilization transformation. Each row represents a single root sample, and each column represents a unique virtual taxon. For clarity only virtual taxa that occurred in three or more samples are displayed. Top column annotation depicts the genus to which the virtual taxa clustered with based on Maximum likelihood tree in figure 1. Asterisk $\left({ }^{*}\right)$ depict virtual taxa differentially significantly abundant between geographical location per DESeq2 Wald's test. Column annotation bar graph depicts the prevalence (number of unique samples) the virtual taxa were found in. The "Association" column annotation is a colorimetric Venn diagram with a $10 \%$ prevalence cut-off where yellow squares represent taxa associated with California samples, blue squares represent taxa associated with Florida samples and green squares represent taxa which were associated with both Florida and California citrus roots. Gray boxes indicate taxa that did not pass the $10 \%$ prevalent cut-off to be associated with either category. Row annotations show which samples belong to each geographical location and bar graph shows the number of unique ASVs associated with each sample. Dk: Dominikia; Fu: Funneliformis; Rz: Rhizophagus; Sg: Septoglomus; Uk: Unknown. 
bioRxiv preprint doi: https://doi.org/10.1101/2022 03.01.482593. this version posted March 22022 The copyright holder for this preprin (which was not certified by peer review) is the author/funder, who has granted bioRxiv a license to display the preprint in perpetuity. It is made available under aCC-BY-NC-ND 4.0 International license.

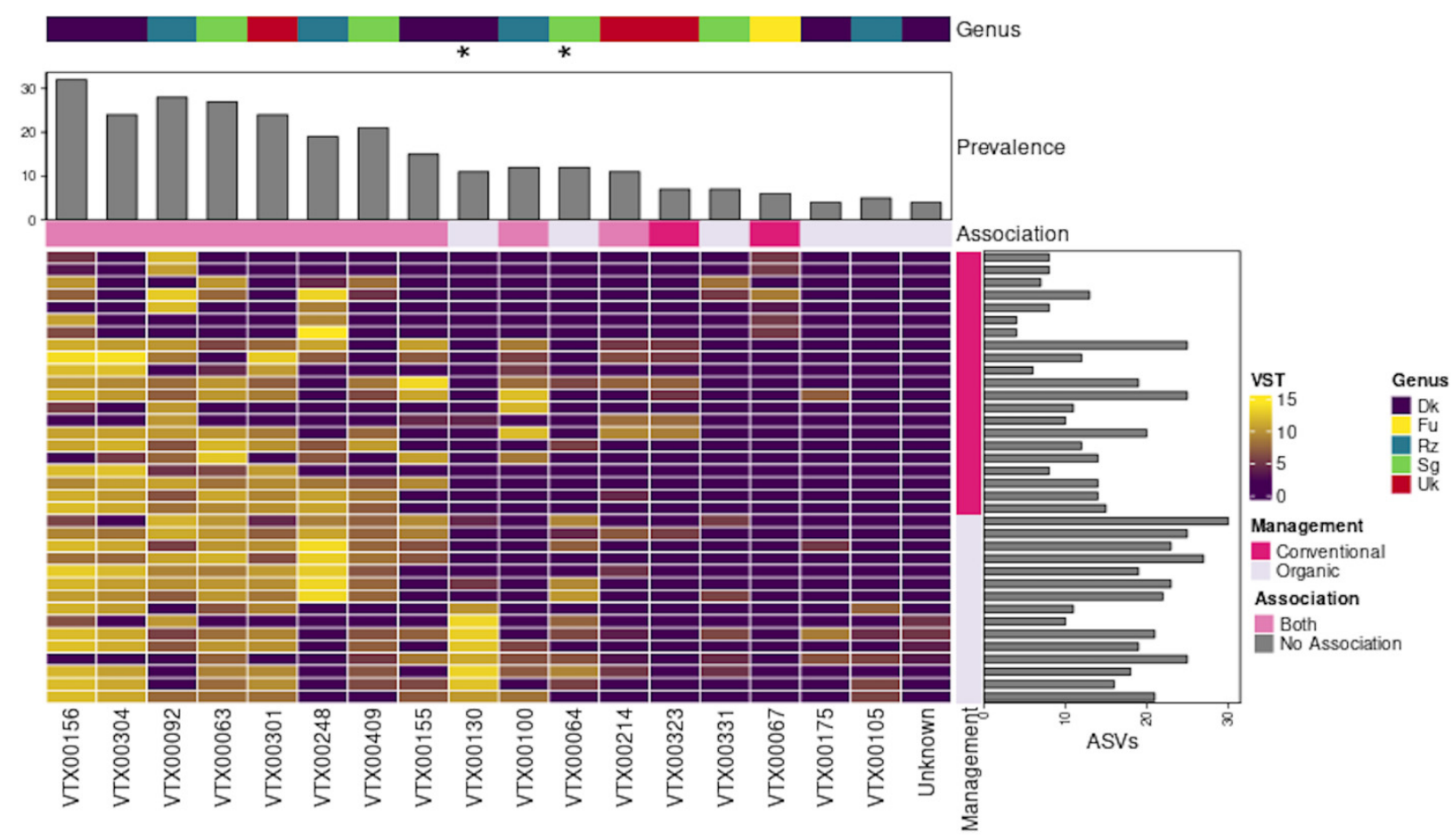

Figure 5. Heatmap of virtual taxa counts between management strategy from California samples following Deseq2 variance stabilization transformation. Each row represents a single root sample, and each column represents a unique virtual taxon. For clarity only virtual taxa that occurred in three or more samples are displayed. Top column annotation depicts the genus to which the virtual taxa clustered with based on Maximum likelihood tree in figure 1 . Asterisk $(*)$ depict virtual taxa differentially abundant between geographical location per DESeq2 Wald's test. Column annotation bar graph depicts the prevalence (number of unique samples) the virtual taxa were found in. The "Association" column annotation is a colorimetric Venn diagram with a $10 \%$ prevalence cut-off where dark pink squares represent taxa associated with Conventional samples, lavender squares represent taxa associated with Organic samples and medium pink squares represent taxa which were associated with both Organic and Conventional citrus roots. Row annotations show which samples belong to which management strategy and bar graph shows the number of unique ASVs associated with each sample. Dk: Dominikia; Fu: Funneliformis; Rz: Rhizophagus; Sg: Septoglomus; Uk: Unknown. 
bioRxiv preprint doi: https://doi.org/10.1101/2022.03 01.482593: this version posted March 2 2022. The copyright holder for this preprin (which was not certified by peer review) is the author/funder, who has granted bioRxiv a license to display the preprint in perpetuity. It is made available under aCC-BY-NC-ND 4.0 International license.

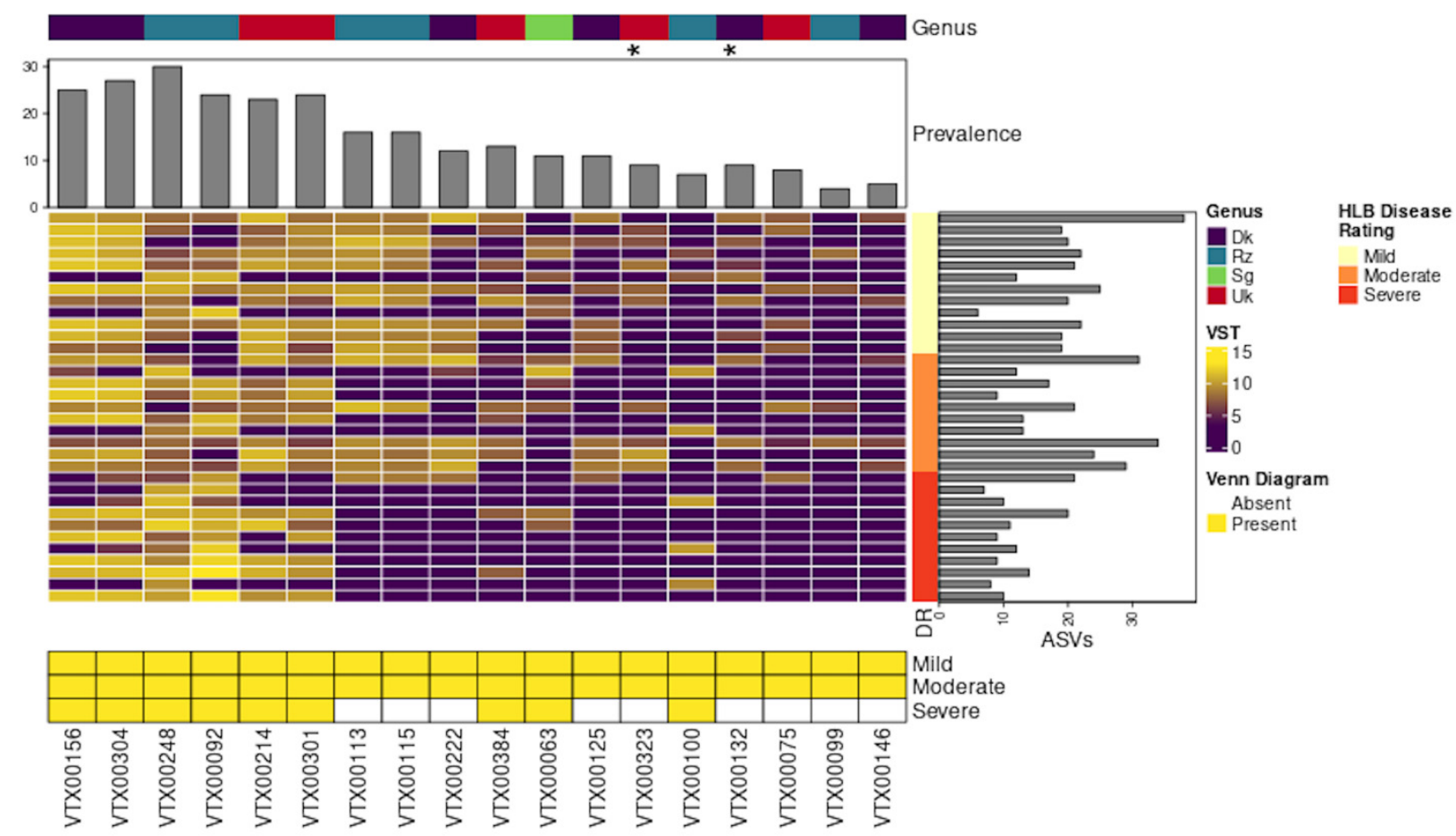

Figure 6. Heatmap of virtual taxa counts of HLB disease severity from Florida samples following Deseq2 variance stabilization transformation. Each row represents a single root sample, and each column represents a unique virtual taxon. For clarity only virtual taxa that occurred in three or more samples are displayed. Top column annotation depicts the genus to which the virtual taxa clustered with based on Maximum likelihood tree in figure 1. Asterisk $\left({ }^{*}\right)$ depict virtual taxa differentially abundant between geographical location per DESeq2 Wald's test. Column annotation bar graph depicts the prevalence (number of unique samples) the virtual taxa were found in. Row annotations show which samples belong to each disease rating severity and bar graph shows the number of unique ASVs associated with each sample. Venn diagram heatmap with yellow rectangles show which taxa were found in at least $10 \%$ of sample from each disease severity. Dk: Dominikia; Rz: Rhizophagus; Sg: Septoglomus; Uk: Unknown. 